\title{
Erratum to: Endovascular Interventions in Acute Ischemic Stroke: Recent Evidence, Current Challenges, and Future Prospects
}

\author{
Ramana Appireddy $^{1} \cdot$ Charlotte Zerna $^{1} \cdot$ Bijoy K. Menon $^{2} \cdot$ Mayank Goyal $^{3,4}$
}

Published online: 27 July 2016

(C) Springer Science+Business Media New York 2016

Erratum to: Curr Atheroscler Rep (2016) 18: 40

DOI 10.1007/s11883-016-0588-z

The original version of the article contains some errors in the numerical data in Table 2. Below is the corrected version.

The online version of the original article can be found at http://dx.doi. org/10.1007/s11883-016-0588-z.

$\triangle$ Mayank Goyal

mgoyal@ucalgary.ca

1 Calgary Stroke Program, Department of Clinical Neurosciences, University of Calgary, Foothills Medical Centre, 1403 29th St NW, Calgary, AB, Canada

2 Calgary Stroke Program, Department of Clinical Neurosciences, Hotchkiss Brain Institute, Cumming School of Medicine, University of Calgary, Foothills Medical Centre, 1403 29th St NW, Calgary, AB, Canada

3 Department of Radiology, University of Calgary, Foothills Medical Centre, 1403 29st NW, Calgary, AB, Canada

4 Seaman Family MR Research Centre, Foothills Medical Centre, 1403-29th St NW, Calgary, AB T2N 2T9, Canada 


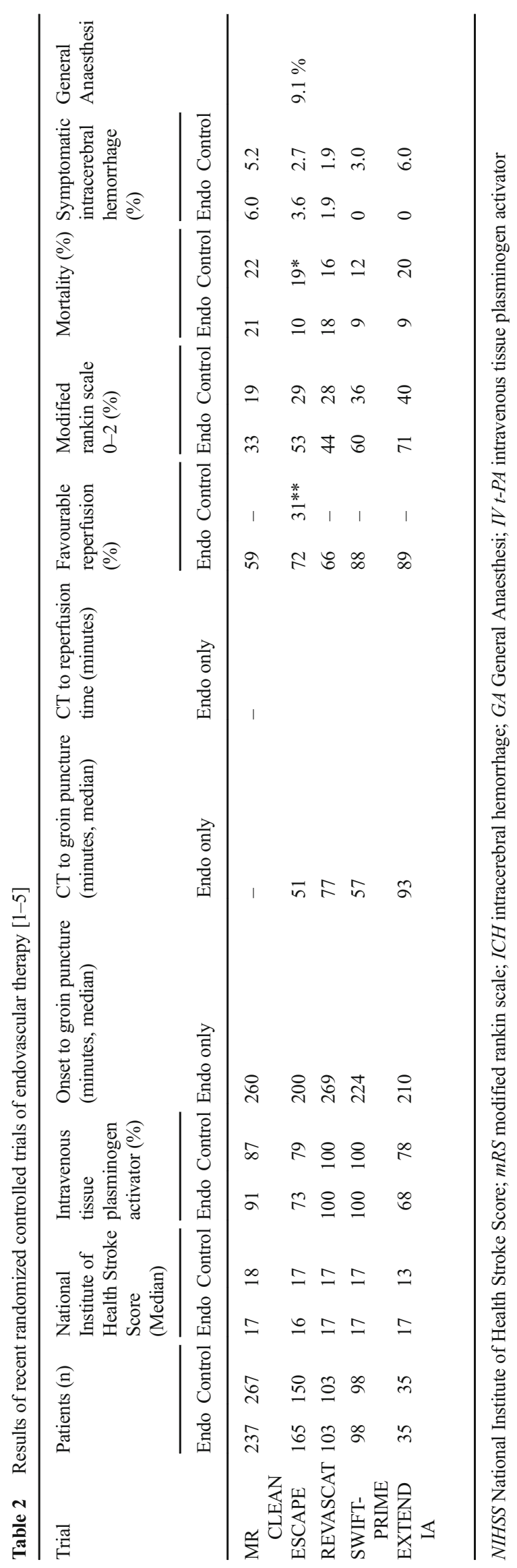

